is principally carried out should be a minimum. The heads of divisions presented alternative proposals which also were not accepted. These proposals were backed by a strong plea that they were the outcome of careful thought by those who had exceptional opportunities of studying the working of the Institute and the needs of the industry. They recommend a complete reorganisation of the personnel and work of the Institute on two main lines : (i) work on the product-chemical; (ii) work on the tree-botanical, including agricultural and both research and advisory work. They envisage four senior scientific officers and one administrative officer working as an executive cabinet under a director, preferably someone quite free from outside affiliations and selected mainly for administrative ability and experience. Such a scheme, if staffed with officers capable of working in absolute harmony, should develop the team spirit essential to success. A selection and a list of temporary salaries were included with these proposals.

In view of the growing recognition of the importance of Imperial research on Empire products, it is disappointing to learn of this serious threat to rubber research and the uneasiness with which scientific workers and others regard the situation will not be diminished by the Board's dismissal of the alternative scheme and proposals put forward by the scientific and technical heads of divisions. The reductions in salary and personnel adopted by the Board appear likely to have an untoward effect on the recruitment for Imperial services abroad generally. In view of the comparatively early age of retirement in such services and the difficulty frequently experienced in securing an appointment on return to Great Britain, such drastic reductions in salaries will deter many promising scientific officers of high ability from coming forward for service abroad.

\section{Ultra-short Wave Technique in Radio Communication}

$A^{\mathrm{T}}$

the International Congress of Electricity held in Paris in July last, some twenty-six papers were read before Section 9 dealing with various aspects of radio engineering, ranging from commercial telephonic communication to the study of the electrical properties of the upper atmosphere. Among these papers, two are of particular interest in connexion with the progress of ultra-short wave technique.

The first of these, by I. E. Mouromtseff and H. V. Noble, describes a new type of ultra-short wave oscillator. This consists of a special three electrode valve in which the cylindrical anode and spiral grid form part of a concentric transmission line, which itself replaces the tuned circuit normally associated with an oscillating triode. For cylindrical conductors the diameters of which are of constant ratio, the inductunce and capacity of the line will satisfy the condition of uniformity of distribution, and when the necessary supply voltages are connected to the electrodes at suitable points oscillations will be set up on the line at a wave-length equal to twice the length of the line. These oscillations take the form of stationary waves giving rise to no external field or radiation, but a suitable open or closed circuit may be coupled to the line, in order to make use of the high frequency power. A large water-cooled transmitting valve constructed on this principle has been made to generate up to 16 kilowatts at wave-lengths of 3 and 5 metres, with an efficiency of from 20 to 40 per cent.

The use of this principle would appear to overcome some of the difficulties of making high-power valves for short wave-lengths, which arise from the necessity of reducing inter-electrode capacity in valve oscillators using one of the ordinary circuit arrangements. Since the reading of the paper in Paris, a more complete account of this work has been published in the Proceedings of the Institute of Radio Engineers for August 1932.

In the second paper, I. E. Mouromtseff and G. R. Kilgore give a description of some experiments on a magneto-static oscillator for the production of oscillations at wave-lengths of $50 \mathrm{~cm}$. or less. The special valves employed are similar to the magnetron type, comprising a cylindrical anode, split longitudinally into two parts, and containing a straight axial filament. This valve is placed in a suitable coil supplying a constant magnetic field in the direction of the axis. The two halves of the anode are connected to two parallel wires forming a Lecher wire system which can be adjusted to resonate at the desired wavelength. Yagi and Okabe had previously remarked that, in the ordinary magnetron, when the conditions were such that the electrons passed very close to the anode without touching it, weak oscillations of a very high frequency were to be observed.

The present researches show that the intensity of these oscillations can be enormously increased if the direction of the magnetic field is altered by a small angle from the axis of the valve electrodes. Graphs accompanying the paper referred to above, show that the oscillations attain a maximum intensity for angles between $2^{\circ}$ and $10^{\circ}$, depending upon the dimensions and operating conditions of the valve. Examples are quoted in the paper of valves capable of producing oscillations of appreciable intensity at wave-lengths of 22-55 $\mathrm{cm}$.

R. L. S..R.

\section{University and Educational Intelligence}

Birmingham.- The Executive Board of the Birm. ingham Hospitals Centre, of which Sir Charles Grant Robertson is chairman, has decided to proceed immediately with the provision of the new hospital at Edgbaston on the site of 100 acres adjoining the University given by Messrs. Cadbury Brothers. The first instalment is to consist of 500 beds. This scheme (which has been suspended for many months in consequence of the national financial stringency) is of vital importance to the University, the Medical School of which is to be housed in buildings forming part of the hospitals centre. It has been disclosed that a contribution of $£ 52,000$, hitherto anonymous, was made by Sir William Morris (of Morris Motors Ltd.) on the understanding that the work should be begun by January 1, 1933. A donation of $£ 100,000$ was made by Mr. Harry Vincent, treasurer of the fund, and another contribution, by an anonymous donor, of $£ 50,000$ has been received. The total cost of buildings and equipment is estimated at above $£ 718,000$, of which more than $£ 647,000$ has already been contributed or promised.

Cambridge.-The General Board has recommended that vertebrate zoology be added to the list of subdepartments in the Department of Zoology, with the reader in vertebrate zoology as director of the sub.

No. 3292, VoL. 130] 